\title{
Intimacy in Long-Distance Relationships over Video Chat
}

\author{
Carman Neustaedter \\ School of Interactive Arts + Technology \\ Simon Fraser University \\ $102-13450102^{\text {nd }}$ Avenue, Surrey, BC, Canada \\ carman_neustaedter@sfu.ca
}

\begin{abstract}
Many couples live a portion of their lives in a long-distance relationship (LDR). This includes a large number of dating college students as well as couples who are geographicallyseparated because of situational demands such as work. We conducted interviews with individuals in LDRs to understand how they make use of video chat systems to maintain their relationships. In particular, we have investigated how couples use video to "hang out" together and engage in activities over extended periods of time. Our results show that regardless of the relationship situation, video chat affords a unique opportunity for couples to share presence over distance, which in turn provides intimacy. While beneficial, couples still face challenges in using video chat, including contextual (e.g., location of partners, time zones), technical (e.g., mobility, audio/video quality, networking), and personal (e.g., a lack of physicality needed by most for intimate sexual acts) challenges.
\end{abstract}

\section{Author Keywords}

Long-distance relationships, video chat, intimacy

\section{ACM Classification Keywords}

H5.3 [Information interfaces and presentation]: Group and Organization Interfaces - Computer Supported Cooperative Work;

\section{General Terms: Design, Human Factors}

\section{INTRODUCTION}

Long-distance relationships (LDRs) are those where partners expect to continue a close relationship but communication opportunities are restricted because of geographic distance [22]. In present culture, LDRs are fairly common [22]. Work may force partners to live apart because of a "two-body problem" where partners cannot find work in the same city [1]. It may be voluntary, such as dual-career and dual-residence couples who choose to live separately due to career demands, desires for autonomy [25], and/or desires to live geographically close to family. Certain jobs require people to live in different places or to travel for long durations, such as in professional athletics,

Permission to make digital or hard copies of all or part of this work for personal or classroom use is granted without fee provided that copies are not made or distributed for profit or commercial advantage and that copies bear this notice and the full citation on the first page. To copy otherwise, or republish, to post on servers or to redistribute to lists, requires prior specific permission and/or a fee.

CHI 2012, May 5-10, 2012, Austin, TX, USA.

Copyright 2012 ACM xxx-X-xxxx-xxxx-x/xx/xx...\$10.00.

\author{
Saul Greenberg \\ Department of Computer Science \\ University of Calgary \\ 2500 University Drive NW, Calgary, AB, Canada \\ saul.greenberg@ucalgary.ca
}

the military, offshore oil workers, people who do extensive work in the field, or mariners who are off at sea. Crisis (such as ailing parents) may force one person to temporarily reside elsewhere. School studies also separate partners. In fact, studies of college students estimate that about $75 \%$ of college students have been involved in a LDR $[22,24]$.

The low cost and ubiquity of computer-mediated communication (CMC) tools seemingly lessen the limitations of distance. Email, instant messaging (IM), cell phone calling, texting, video chat, and social networking sites all create easy ways for LDR partners to communicate. Media is now increasingly rich, and multiple channels provide support for a range of communicative activities $[9,22]$, including even intimate activities like cybersex [20]. Studies have shown that CMC can ease loneliness [1] and increase feelings of closeness [1], relationship satisfaction, trust, and commitment, while lowering jealousy [5].

Recent studies have looked at the way video chat systems are used by family members to stay connected over distance $[2,10,14]$. However, none of these studies look specifically at the way LDR couples use video chat to help maintain their relationship. We also have seen a number of next generation video systems designed for the home $[11,12,15$, 19,29], however, their focus is not on connecting couples in LDRs. Thus, within this sphere, there has yet to be any focused study of how partners in LDRs make use of video chat systems to help maintain their relationship.

Our paper focuses on understanding and documenting this niche. In particular, we investigate how couples in serious LDRs (as opposed to casual dating) make use of video chat systems to help maintain their relationship. Our emphasis is on documenting the core practices of LDR couples to show how video affords unique opportunities for intimacy, a shared sense of presence, and even intimate (and sometimes sexual) interactions. This presents a detailed foundation for future design work. First, we outline related work on long distance relationships and studies of video chat systems. Second, we describe our interview methodology. Third, we step through our findings to illustrate the benefits and challenges that LDR couples face with video chat systems when used in a (somewhat) "always-on" setting. We conclude with a starting point for discussions about the impact of these routines for design.

\section{RELATED WORK}

Relationship maintenance is the cornerstone of all couple 
relationships $[4,22,24]$. Whether people notice it or not, many of their common everyday activities relate to relationship maintenance. This includes positivity (e.g., being polite, avoiding criticism), being open, providing assurances about the relationship, expressing one's love physically, managing conflicts, and sharing tasks or chores [4]. When it comes to LDRs, the same basic relationship maintenance strategies are used $[4,7]$.

Relationships will deteriorate if people do not actively work to maintain them using some or all of the above maintenance activities [4]. In fact, studies have also looked at the factors that relate to relationship satisfaction and they are very similar, if not the same, as the maintenance activities [28]. Such factors include satisfaction with communication, influence in the relationship, sexual activities, one's leisure (the way each partner spends free time), division of household tasks, time together (just the two partners), time with other friends/family, and finances [28]. Of all of these, satisfaction with communication is the strongest predictor of marital satisfaction [28].

A common assumption is that partners in LDRs are not as satisfied with their relationship because of the distance [22]. However, this is most often not the case: People find ways to achieve the previously mentioned relationship behaviors in spite of being separated by distance [22]. Relationship satisfaction in LDRs can also be explained by comparing the communication in LDRs with that of geographicallyclose relationships. Many relationships (regardless of distance) begin with partners seeing their relationship in an idealized form [28]. This view typically deteriorates over time as partners increase self-disclosure and become more open with each other [4]. But LDR partners often hold off on this degree of disclosure, talk more positively about their relationship, and avoid conflicting topics [23,26]. When together, LDR partners may be on their "best behavior" in order to cherish their time together [5]. Thus, LDR partners are just as satisfied with their relationships as geographically-close couples because they avoid conflict $[4,23]$. Studies of LDRs that become geographically-close show that once partners are together, they open up, discuss more conflicting topics, and the idealized view of the relationship dissipates [25]. In fact, this is one of the main reasons that a third of LDRs that move to geographic proximity end within three months of reunion [25].

CMC technologies have changed the nature of LDRs by providing an ever-increasing range of ways to be connected. Access to a remote partner is now faster and cheaper than ever [6]. Novel research prototypes are even being designed to specifically target couples and the need to maintain their relationships over distance. For example, couples can now share melodies over their cell phones [21] or click to say, "I love you" [13]. However, such CMC technologies are not without their challenges. Scheduling times for communication over such channels is not always an easy task [1] and is certainly more problematic than 'bumping into' one's partner while at home. Many communication channels are also not very rich when compared to face-to-face situations.

One technology that does show promise, given its similarity to face-to-face settings, is video chat systems. A variety of studies have explored this space and illustrate the ways in which families make use of the technology and the challenges associated with it. First, studies have shown that feelings of "being there" are one of the largest benefits of video chat [2] and such systems make people feel closer to the remote person than other CMC technologies [14]. Second, we know that some people will leave their video link open for an extended period of time [10,14]. This occurs most often for families with children so that they can "share everyday life" with remote family members such as grandparents [10]. Third, studies have shown that it isn't easy to initiate video calls and people commonly use other technologies like the phone or instant messaging clients to first check the remote party's availability and willingness to video call before calling $[2,10]$. In some cases, people will stay 'offline' until they receive such a request [10]. Once calls are established, people face additional technical challenges in keeping the connection going [2,14].

Our own research builds on this related work. Given that video chat has already been shown to be left open over long periods of time, we wondered if and how this practice might extend to couples in LDRs. That is, how does the richer communication channel afforded by always-on video - or "hanging out" via video — support relationship maintenance over distance? Are there social and technical challenges introduced by this technology that affect its use in LDRs? This is the focus of our inquiry, described next.

\section{METHODOLOGY}

We conducted semi-structured interviews with fourteen people in LDRs, focusing on their use of video chat .

\section{Participants}

We recruited participants through snowball sampling, word-of-mouth, presentations on related topics, and ads on Facebook, Twitter, and an online forum devoted to LDRs. We selected participants who already used video chat as a primary technology for communicating with their distant partner, preferably where they kept a video link open with their partner for extended periods of time. We did not select for a particular kind of LDR relationship dynamic, which meant our sample included a variety of relationships, e.g., dating, living together, engaged, married. As is standard in qualitative research, we recruited and interviewed participants iteratively. Our interviews ceased once we no longer saw new practices emerge.

Participants ranged in age from 19 to 35 years old and half were female. Two participants were in same-sex relationships (one male, one female). All participants were in serious relationships (albeit to a varying degree). All participants currently resided in either the United States or 
Canada, but some were originally from other countries. The geographical distance between partners varied heavily. The closest couple was a two-hour drive apart. The furthest had partners across the world, where they were separated by large time zone differences of 10-12 hours. Due to our recruitment process, about half of our participants were graduate students, post-doctoral fellows, or researchers; yet, their partners' occupations varied broadly.

\section{Interview Method and Analysis}

We conducted semi-structured interviews with each participant individually. Only 2 of the 14 were part of the same couple and were interviewed separately. Interviews lasted between 60 and 90 minutes. Five interviews were conducted over Skype and nine were conducted in person in a private office. Questions explored participants' relationships and routines in detail, their use of video chat systems, and their use of other CMC systems in comparison to video chat. We kept handwritten or typed interview notes and audio recorded all interviews. The focal points of our interviews were transcribed and the remainder of the audio was used for reference as needed. We inductively analyzed our interviews using open, axial and selecting coding [27].

What we found remarkable with our participants was that each, regardless of the relationship dynamics, was able to maintain large degrees of intimacy in their LDR because the video channel afforded unique opportunities to connect the partners' physical locations and created a shared sense of presence between the partners. In the following sections, we document this along with the social and technical challenges that participants faced in using video chat. Again, our emphasis is on providing descriptive details on the routines of our participants.

\section{REASONS FOR USING OTHER CMC MEDIA VS VIDEO}

Participants used a variety of CMC technologies to connect with their distant partner. Each fulfilled a specific need. They commonly used SMS texting for short greetings such as "Good Morning" or "I love you", quick questions during the day, for security where some would check to ensure their partner had made it home safely, and (for some) just to stay in somewhat constant contact. Instant messaging was similar, yet it also afforded asynchronous conversations over a longer time period, such as while one of the partners was at work. They used email (or Facebook private messaging) for sharing stories or funny items, reminiscing about their relationship, coordinating tasks such as paying bills and planning trips, or reviewing documents. They used the telephone for deeper conversations, where partners needed to focus on one another and their discussion. This might include talking about their relationship or other potentially emotional topics. They said it was also useful for short and timely interactions, because it was fast to phone someone. They predominantly used cell phones in situations when one or both partners were mobile.

Participants most often used Skype or Google Chat to video chat with their partners and video chat played a somewhat different role than other technologies. All participants stated they had used video chat as a communication tool for their relationship either before they became separated by distance, or immediately after moving apart. A few began using video chat for pragmatic reasons, such as that it was faster to simply talk rather than type, and that Skype calls were free. In those few cases, video usage began because it was a byproduct of these voice calls, but then became more valued over time. However, for the vast majority of cases, and as one might expect (and similar to families' use of video chat $[2,10,14]$ ), people primarily wanted to see the other person when apart, and share their day-to-day life by hanging out together. Both provided an additional level of emotional connection that other CMC technologies could not provide. We provide details in the following sections.

\section{VIDEO CHAT IS FOR SEEING}

First and foremost, they simply wanted to see their partner's face, as it made them feel emotionally closer to each other.

"I could not stand not seeing my husband. I mean, I needed him, I needed to see him, and actually everyday we also talk by our cell phone but it's not enough for us. I need to see his face. And he also has the same feeling"- P12

"The voice is not enough. The relationship is so physical and visual. It's not just about hearing and talking." - P13

They also described video as a way to see their partners' facial expressions and body language. In some cases, this helped avoid miscommunications.

"I always apparently sound pretty harsh when I'm talking ...even when I'm joking it doesn't sound like I'm joking...I would sometimes upset her without even knowing I upset her and, of course, without intending... With video, the problem I had on the phone goes away because she can see that I'm smiling, she can see that I'm being supportive, she can see that I'm not frowning or being angry at her, so you know in that kind of sense it removed those obstacles." -P3

“You don't have to talk. You can see smiles." - P13

"It's just that if you see someone you feel it's real ... you see their reaction instantly. With audio it's harder to get the same information of how someone feels. " - P14

They also said that video helped them see the emotional demeanor of others. One participant said that seeing their partner looking tired and worn out helped him understand her state of mind, where he would empathize with her.

Video helped them see their partner's surroundings, whether it was just part of the background or purposely shared by giving the other a video tour around the area.

"It's really nice to see where the other person is situated... she's always at home but it's nice to see she's at home, see cats running around in the background." -P1

Partners commonly "showed off" new things visually over video chat. This ranged from haircuts to modeling clothes and glasses they just purchased. 
Some people were very aware of their appearance. Even though they shared intimate relationships and had seen each other "at their worst," three participants would only video chat after they had made themselves "look good."

"We kinda prepare to see each other. One thing we found really bad is seeing each other right after waking up. " - P5

"I just feel like I'm on stage when we're on Skype. And I know I look different when I'm on video. It's not like being in person...Having to be confronted with how you look continuously is different than having a face-to-face conversation with someone. You're more aware... I still like put makeup on and do my hair before Skypying..." - P6

Overall, participants said that they used video because it created a unique sense of presence with their partners. In fact, this was one of the fundamental reasons that many couples used video, and only part of this relates to seeing. We return to this in subsequent results.

\section{A MATTER OF ROUTINE: INITIATION AND TIMING}

On the downside, video chat was seen as more challenging to initiate a connection with than other technologies. Thus, it was used more commonly in situations when both partners had the time to stay connected for longer durations. People managed this by the way they initiated and timed their video chat sessions.

Like other studies of video chat $[2,10]$, we also found that nearly all of our participants would use other technologies to check if their remote partner was available to video chat prior to video calling them. This varied between using text messages, the phone, or instant messaging to find out if the partner was in a location conducive to video chat (e.g., at home vs. work) and if they were not busy. While some used the IM capabilities by staying online continuously, others did not as they did not want to be available for video-calls by people other than their partner.

However, most video chats were not totally serendipitous or one-person initiated. Instead, partners developed routines of when they would be available to each other. Much like a couple living together, they would try and expect to see each other once they had arrived at home after work or school in the evenings, or early mornings, or at other key times during the day. For example, one couple said they usually contacted each other in the evening, just after dinner, and kept the connection open for an hour or two.

Yet time zone differences - which is a fact of life for LDRs living far apart-strongly influenced how they fashioned their video call routines. Usually this meant juggling their schedules to fit their windows of opportunity, e.g., compensating for mismatches between when they would get up, arrive or leave at work, have dinner, or go to bed. A bigger issue is that the larger the time difference, the fewer the number of hours they would have together. For example, a couple in the same time zone would often have three or four hours to spend together in the evenings. Yet a couple with a partner on (say) each coast of North America might only have one hour to spend together before one had to go to bed.

Extreme time zone differences (e.g., 10-12 hours apart) introduced further challenges. Our four participants in this category worked around this, but it was not always easy. The first participant had a partner who worked from home so they would routinely video call while she was at home during her evening and he was working during his morning. The second couple had work schedules that were aligned so that they both had the same six hours off of work together; for one this was in the evening, and for the other it was in the morning. The third couple did not work so they could alter their sleep schedules to be awake during a larger time overlap. The fourth couple had no such options because both had fairly rigid work times. To compensate, they scheduled their video time together on the weekend.

\section{HANGING OUT: DAY-TO-DAY SHARED LIVING}

We purposely tried to recruit participants who used a video chat system for extended durations of time, and, as it turned out, all but one participant did indeed do this. This participant simply did not have enough overlapping "free time" with his partner to allow them to stay connected for more than an hour at a time. On the other hand, all of our other participants "hung out" with their partners over video links for several hours at a time. The video link supported two primary behaviors: partners doing different activities in parallel where the video link provided a view onto each other's activities, and partners doing shared activities together. We describe each in detail.

\section{Parallel Activities}

Eleven participants described doing parallel activities with their partners over a video chat system. That is, partners would be connected over a video link but each would be doing his or her "own thing." As in day-to-day domestic life, parallel activities varied, but included house-cleaning, work, cooking, eating, reading, playing games, or watching television, where each partner would be doing a different thing on his or her own. Sometimes activity would occur in front of the camera, and other times it might only be visible over the link part of the time. Partners would periodically look to see what their remote partner was doing.

"Once [video] starts I just kinda sit back in the sofa, put the laptop on the coffee table, eat dinner, watch tv, sometimes do work (on my other laptop)... Most of that time she's off playing her own games on her phone or iPod... she might stream something from NetFlix... and she's just there on the screen. " - P3

Conversation routinely would come and go during video sessions containing parallel activities. That is, partners might periodically get the attention of the other person and talk to them. Otherwise, the two were not normally engaged in conversation.

"I would sometimes be reading or something while we'd be on video ...we'd just have [Skype] open, and sometimes 
we'd not really say anything for like 15 minutes, 20 minutes you know but I'd be able to talk to her. So it was kinda like being in the same room as her but not necessarily interacting actively. " $-P 2$

"Usually he's sitting on the couch and eating some kind of snack or dinner ... if there's something that we need to say to each other we'll chime in every now and then. It's almost like you're sitting and watching TV together...Typically it's we keep it running and live our lives kind of deal. And it's typical evening stuff, making dinner, making sure things are cleaned up, getting things ready, taking care of personal business, stuff like that." - P7

Some participants even said they muted their microphone so that unnecessary sounds from their end were not transmitted, such as a TV, music, or keyboard typing. If they wanted to get their partner's attention, they would just unmute their microphone.

"We use video as a method to simulate shared living. Even if we aren't talking, the video channel is open. In fact, even when open it is on mute most of the time ... We do the things we would normally do if we were together and can see one another doing it." - P10

Regardless of the specific activities that were occurring, participants predominantly told us that the purpose of having the video link open was to simply feel the presence of their remote partner. This made them feel more comfortable and even closer to their partner.

"At home, a lot of times at night, he likes to put on his pjs and turn out all the lights and sit there with a snack and, you know, watch TV. So sometimes it's hard to see him but other than that, as long as you can see the form of somebody that's a nice thing. I think it's just the comfort of knowing that they're there." $-P 7$

\section{Shared Activities}

Seven participants talked with us about doing shared activities - beyond talking — with their partners over a video chat system. These activities formed a core part of their relationship maintenance. Routine shared activities usually occurred during weekday evenings $v s$. the weekend, as weekend schedules were less predictable. Several activities are listed below, where all reported the same benefit: they would be doing a routine, everyday activity together.

Watching Television or Videos. Seven participants watched television or videos together. This often involved them placing a laptop or computer near or in front of a couch and then broadcasting their reactions to the show to their remote partner. Sometimes remote partners would watch the same show if they had the same channels. Other times, they might watch their own show. Some participants would even try to synchronize the watching of movies together.

"We video Skyped while we both had this movie and we watched it at the same time ... we were like Skyping at the same time so we could see each other's reaction, like he was small and in the corner so I could see his reaction...it was nice, I actually mentioned it to him the other day that I wanted to do that again, it was nice because there was more of the idea that the person was there... that was a very prime part in our relationship ... I could see him laugh at the funny parts or I could see his reaction to something ridiculous. " - $P 9$

Two participants watched music videos together so they could both listen to the same music at the same time. In these cases they would share links to YouTube videos and then both try to synchronize the starting of them. Both participants enjoyed seeing their partners' facial reactions to the songs and videos over their Skype connections.

Three issues arose when partners would try to watch shows or videos together. First, partners who tried to watch the same interactive content (e.g., online streaming of TV shows, YouTube videos) found it difficult to synchronize them. One couple resorted to counting down numbers from 5 to 1 out loud before hitting play. Second, if the show/movie was watched on a TV, then it was easy to see the remote partner on the separate computer. Yet if the show was being watched on the computer, participants would have to toggle between seeing their partner and seeing the show, or strategically place the video window such that both could be seen (if this was even possible with the participants' software). Third, audio was a significant problem; sound from the show or video would broadcast over the video link at the expense of the partners' voices. This created duplicate (and somewhat unsynchronized) sound if the partners were watching the same show.

"What happens is both of us watch TV a lot, so when she streams she mostly streams Netflix...the audio comes through really loud... my volume of her is at 5\% so I can [only] hear her if she says 'hey' really loud." - P3

"The reason why we watch together is to see and hear each other's reactions for the shows that we like so much. And that's the crappy part about Skype and watching TV together because you can't talk because the audio is soloud from the show on both ends ... When we were [face-toface], it was like constant conversation and making jokes and laughing about stupid things people say...it's more like a tool to get to know each other." - P6

Sharing Meals. Two participants were fortunate enough to have similar enough time zones and eating schedules that they could occasionally sit down together and eat dinner over Skype. One described this as being similar to the way a collocated couple might routinely eat together as opposed to a date or special occasion.

"This year we started video chatting and having dinner, which has been nice...it'll be a sushi night and we'll get sushi and ahh, umm, so yah, as much as we can to sort of normalize this ridiculous long distance relationship we try...In a way we both know that it's not a date, it's just we're having dinner together in front of Skype." - P9 
Playing Video Games. One participant described how he would play video games on his computer with his distant boyfriend. Being able to see him periodically over the video link added to the gaming experience.

"Most of the time we have the window in front of the video anyhow where we're not just really watching exclusively the video...But you can just click over and see him." - P10

Time with Others. Nearly all shared activities occurred between just the two partners; rarely did they ever have other friends participate in their shared activities. In fact, most participants said that they compromised the time that they spent with other family or friends, and would instead spend the majority of their spare time with their partner.

\section{LOCATION AND ENVIRONMENT}

We saw several important instances where the location or environment affected the use of video chat in relation to privacy, mobility, and varying situational contexts.

Private vs. Shared Dwellings. Video chats predominantly occurred from within the participants' own homes or dwellings. For those who lived alone (which included the majority of our participants and their partners), they could easily hang out over video chat without family members or roommates observing. Those who lived in shared dwellings with either family members (e.g., parents, siblings) or roommates had other concerns. Somewhat surprisingly, while our participants did exhibit some privacy worries, they were often more anxious about disturbing their roommates. Consequently, they would try to video chat within a private bedroom as opposed to a communal room.

"Normally I'd just be in my bedroom... we had a living room and dining room but they were a really big open communal space and there'd be other people there. A lot of the times if I was on video people would be bothered by me talking. So typically I'd just be in my bedroom." - P2

To ensure privacy, some participants used other technologies before initiating a video call to check if other people were around. They also reported adjusting their computational and physical environment to safeguard their partner's privacy when others were around. For example, one person (who was in a private dwelling) described how her remote boyfriend would adjust his environment to make her comfortable with his roommates:

"There are sometimes if I am already in bed and I'm like in my pjs and stuff I'm not necessarily the most comfortable with his roommates seeing that...so [my boyfriend] will umm you know like push down his computer screen or just minimize the video because he knows about my comfort levels. Usually if we're talking about something more personal he'll just close the door and his roommates will know not to bother him or they'll knock first." - P9

Of course, the challenge here is that the girlfriend must rely on her remote partner to adjust his environment in order to ensure her privacy is not compromised.
Fixed vs. Mobile Locations. When spending time together over video, nearly all participants used a laptop to run their video chat system; only two used a desktop computer. However, many participants would leave their video chat system running from a fixed location in their home even if it was on a laptop. They reported that laptops were not really mobile: they were too cumbersome to move given their weight, the auxiliary wiring, or a deteriorating battery. Some considered fixed locations simply as "good enough."

Others found great value in being able to easily move a laptop around the home. They would typically bring the laptop into the room they were in so their partner could still see them and "be present" in the same space. This included moving the laptop between the living room, kitchen, bedroom, and even bathroom. For example, several participants described how they would bring their laptop into the bathroom when showering or putting on make-up. Here the act was not typically sexual in nature.

Regardless of whether the computer was stationary or mobile, many participants periodically rotated their camera or laptop (with embedded camera) to the general direction they were located in so their partner could see them.

"While I'm not in the living room, I basically turn the laptop so she can see me in the kitchen. I turn the laptop when I'm sitting on the sofa." - P3

"Sometimes he'll be playing a video game in which case he'll turn the camera to face him. But most of the time this is his world of me ..." - P10

Connecting at Work. Five people said they connected with their partners either from their own workplace or to their partner's workplace. Participants were conscious of intruding on work activities or being noisy or distracting to other co-workers who might also be present. As a result, most used earphones or microphones to control audio. One participant told us he would only connect with his fiancée over Skype from his work on weekends, as others were not typically around. Another participant only used Skype from work in the early morning before her colleagues arrived.

"I can video chat at work for a few minutes if I need to. And if no one is around I'll do the same kind of thing [hanging out] ...I'll turn on my video chat and just do my [work] and that way I can see him." - P7

One participant told us that because of the extreme time zone difference she could only see her boyfriend while he worked. On at least one occasion, this created an interesting situation because of the mixed home-work context:

"Last night I was watching something on TV and he had a meeting and uh he just cut my voice... I could see him and of course the person he was meeting with couldn't see me but I was just, you know, doing my own thing and no sound but we could see each other... his office is in his house. I was minimized so the person with him couldn't see what was happening on the computer. I just look at him once in a 
while and then he comes back and tells me he is done and I shush him because I am still watching TV. " - P4

Several participants did not connect from or to their partner at work, and some were even adamantly opposed to doing so. One participant comments:

"I tried to call her at work once. She was just really embarrassed and was like 'why are you trying to call me at work.' We only ever talk from home...I think maybe just because there are other people around. It's kinda like how you don't want to talk on a cell phone on a bus because you don't want to disturb people and maybe you don't want them listening in on your conversation. And I think that's even more so when there is video involved." - P1

\section{CONVERSATION \& (LACK OF) IDEALIZATION}

All participants said that they talked with their partners over video chat before, after, or periodically during their time together. Conversations covered nearly any topic, including day-to-day activities, mutual or non-mutual friends, family members, problems at work, finances, trip planning, sports, and hobbies. Video chat supported such conversations for the most part, although some commented that maintaining eye contact was a challenge.

As mentioned, previous work in LDRs reported idealization behavior, e.g., partners tend to talk more positively, avoid conflicting topics, and be on best behaviours [23,26]. This contrasted with what our participants reported. Nearly all talked about discussing negative topics either at the onset of their time apart or within a few weeks of it. This included discussions of relationship issues, religion, or problematic finances. Several people even openly argued over video chat and felt that it aided their ability to argue.

"Even when we fight we prefer to fight online and see each other because we can see the facial expression of the other person...I think in some cases it can make it worse. In some cases, it can soften it, depending on our reactions really. If say I get so upset I'm bursting into tears, he calms down. Or if something is happening and I'm getting really angry and I'm just ignoring him, he gets more angry so really it depends on the reactions of the person. But the good thing about it is you can see the other person's facial expression because it gives you an idea of what the person is feeling at that moment. If we want to hurt each other more we can, if we want to calm down more we can." - P4

A few purposely chose not to argue over video chat, even though they would sometimes talk about negative topics. One participant did not want her partner to see her face when she was upset with him, not wanting to "give him the satisfaction." Two participants felt that video chat would force them to stay in front of the camera and this did not match their preferred style of arguing, which involved moving between rooms to "get away" from their partner.

"I would never want to have an argument on Skype. I'd much rather have an argument over the telephone... when you're on Skype, you are expected to look straight into the camera. A lot of my argument style involves not looking at the other person." - P6

Another participant commented that video chat did not enable her and her husband to resolve an argument the way they might in person. Typically they would leave the same room during an argument and then return to kiss or hug the other person. Such physical touch is not possible in video chat systems. Yet we did see one couple produce a workaround with a similar effect: They would argue over video chat, but then send resolving terms of endearment through a different medium, be it text or instant messaging.

\section{INTIMATE AND SEXUAL ACTS}

Participants also told us about shared acts that they would do together over video that were of a more intimate or sexual nature. These fell into several categories.

Hugging and Kissing. All but two participants told us that they would express their love with their partner by virtually kissing or hugging them over the video link. This occurred at the end of conversations, but also periodically if the moment warranted it. In spite of problems caused by the separation of the camera from the screen and/or video window, people found workarounds. They or their partners would blow kisses in the air, kiss the area in front of the laptop screen, or hold their arms out as though they were hugging the person in real. One participant even said his partner would stroke his head and shoulder by cupping her hand around his video image and moving it up and down.

"Every now and then like every night we'll typically sign off by giving each other kisses, which is actually like kissing the webcam so it actually looks like you're kissing. If you kiss the screen you get the other person's forehead. Sometimes we'll pretend to hug the laptop. And... surprisingly... it's not like getting a real hug, but it is kind of rewarding in a way." - Pl

"I'm trying to kiss her on the camera... and sometimes she opens her collar and says 'kiss me here'." - P11

For many, kissing and hugging over the link was intimate. Yet a few thought it wasn't serious, where it brought more humor to the relationship and moment.

"I'll make a kiss face at her over video sometimes. I have like hugged my computer and made it look like I was hugging the video but normally this is something I'd just do because it was silly to make her laugh." - P2

Going To Bed / Falling Asleep. Six participants told us that they would sometimes watch their partner fall asleep, or vice versa. These partners would be using video chat during the evening until the point when one of them would be ready to go to bed. That person would then bring their laptop into the bedroom and set it so that it could capture them falling asleep. In one instance, both partners fell asleep together because they shared the same sleep pattern and time zone. 
"I will move [the laptop] to my bedroom. The light is on normally because if I don't turn it on he can't see me... and he normally cuts his voice off so I don't wake up from his phone calls or him talking to people. And at a point in time the computer goes to sleep....it's on the bedside table and I normally position it towards my face." - P4

They also reported several issues. Video quality often deteriorated significantly because of the dark room. Some used the lit computer screen to illuminate themselves (and also to see their partner as they fell asleep), but at the cost of a bright light affecting their slumber. Location and equipment stability was problematic. They said they had to carefully place the laptop (and camera) on a stand, chair, pillow, or blanket so that it had the right camera angle to capture themselves, all while ensuring it didn't shift or fall over. Some participants were also cautious because their laptops might overheat on bedding.

“Often she'll have it in her lap... and then she pulls up a chair next to her bed and she places the laptop on that chair... and then she just kinda falls asleep that way. " - P3

“When you're on a desk you're alright, but that time I wanted to go on the bed and everything was more soft and would move. This was hard. This was a challenge... because the camera would just fall off... because it was on a soft pillow or on the blanket." - P8

Sexual Activities and Nudity. Only two participants said they regularly engaged in full cybersex activities with their partner, where the participants and their partners would both mutually satisfy themselves through masturbation. One of these participants commented that even though they had cybersex, it highlighted the challenges of the act more than anything. They realized more fully that they couldn't actually touch each other and this caused them to miss each other more. For the other couple, cybersex became so important that it was necessary to see the remote partner to be sexually satisfied. Two other participants had tried cybersex, but stopped because it became "awkward."

The ten remaining participants had not tried cybersex for a variety of reasons (we did not notice any obvious gender differences). Several said either they or their partners were too shy to engage in cybersex. Some simply felt it was not a core need for their relationship. Privacy was a concern: two participants didn't want their partners to get completely naked because they had a fear that the video might somehow be recorded or seen by others.

"I feel it goes back to that culture thing, the shyness... you feel like it's not right. Maybe he feels more distant when he's on the video." - P4

"I felt a little uncomfortable about trying to touch myself on video. I didn't feel very comfortable or in the mood.” $-P 8$

"We attempted to have video chat intimate relations and it was very awkward and didn't work out...Maybe it's because I'm insecure but I don't want to look fat or
unattractive...I'm a little square in the corner and he sees a lot more of me than $i$ do. I just can't stop thinking about it and so it decreases any other enjoyment that I might get out of it. " - P6

Some people reported using nudity to visually tease or emotionally connect to their partner as opposed to a physical sexual act such as masturbation. For example:

"But I did like to just strip tease and have this fun with the video and just showing parts of clothing or parts of skin. Like playing with the frame... I'd step away and just show my bra...or showing my back so not really showing everything but still teasing." $-P 8$

However, others disagreed, as sexual nudity without physical proximity did not have the same intimate connotations. As one participant noted:

"Maybe it's like I'm being watched or something. A lot of times when people ask do you have intimate stuff going on online I always think to myself that they are talking about a porn movie. I don't want to be in a porn movie for my boyfriend... he could just go watch a porn movie, why should I do it .... there's no real intimacy after that." - P4

One participant found it easier to "talk dirty" with her boyfriend over IM because of her shyness. She also had "phone sex" with him on a few occasions and thought this offered more of an exchange than video cybersex because it produced more feelings of equality. Another participant commented that the use of the phone was more intimate because it was like "whispering" in his fiancée's ear.

In addition to intimate sexual acts, three participants also talked about seeing their partner either nude or partly naked at times, either while changing or coming out of the shower. In these cases, the viewing was not sexual in nature.

"There were a few times where if I was changing or whatever if I was putting my pajamas on I'd just pull off my clothes and not bother to turn the camera off. It wasn't in a sexual context... and she does the same thing. " - P2

Overall, cybersex was a very personal choice that depended on the couple's values, perceptions of the video media, and the degree they could emotionally connect (or not) over a progression of cybersex activities. For most, the discussion centered around intimacy: the degree of cybersex involved - whether via hugging, kissing, virtual touching, nudity, or masturbation - was more a projection of how that cybersex supported or interfered with feelings of intimacy.

\section{DISCUSSION}

We now discuss our findings and highlight a series of core problems that suggest design directions for future systems.

Shared Living. First, our study reveals a pattern of communication that has moved beyond phone call-like usage. Regardless of the relationship situation, couples appropriated video technologies in a new way that made more sense to them. They turned video chat systems into 
tools that connected two locations in a more permanent fashion. This in turn produced a shared living experience that modeled face-to-face settings more than other CMC technologies. In this joint setting, partners pursued their independent activities, took part in shared activities, and conversed as needed. When conversing, the video added a crucial element of seeing the other person's face and facial expressions. When performing activities, having one's partner 'around' created stronger feelings of connectedness. Together, this shows that intimacy between couples in LDRs is not necessarily about sexual intimacy. It is more importantly about being able to spend time together, whether people are doing the same activity together or not.

These situations certainly create interesting challenges for technology design. Partners would find great value in being able to move throughout their home while using a video chat system and still be on camera. Yet they currently cannot because of power issues, the mobility of devices, audio and camera capture range, etc. Smartphones with Skype or Apple's FaceTime provide one partial solution to mobility, but issues remain and they introduce their own problems (e.g., holding the camera, framing, audio fidelity). Video capture devices also need to be able to be situated in locations that are less conducive to technology placement (e.g., a laptop sitting on a bed). Present technologies are not designed well for these locations.

Partners also need to be able to perform multiple activities on their device at the same time as using a video chat system. For example, many want to video chat while watching television or listening to music. Google+ now provides one way of synchronizing video viewing while using video chat but it is situated more for work meetings and not LDRs. Audio mixing and cancelling is particularly problematic given the various audio channels available (microphones, video, etc).

There also exist challenges with mixed lighting conditions such as poorly lit living rooms or bedrooms when a partner wants to see the other person but not wake them. This suggests research in image enhancement, camera sensitivity, device/screen design, or illumination balancing.

In addition, many social issues exist that are perhaps more difficult to solve through design. People are hesitant to broadcast video for extended periods of time from work or they may not be allowed to; this forces connections into the evening hours. Sometimes people can work around this by working from home. Yet this brings challenges with connecting mixed contexts. This includes connecting not only work and home, but one person's private home with their partner's shared living arrangements.

Sexual Intimacy. Our findings also revealed that, for many, complete sexual intimacy is difficult to gain over a video channel because there is a lack of true physicality between partners. Video chat systems are simply not designed with cybersex in mind, akin to the way that sex toys are now being carefully designed for aesthetics, embodied pleasure, and intimate experiences [3]. Clearly partners need better ways to physically interact over distance as cybersex is extremely limiting. For physical acts such as kissing, hugging and touching, the separation of the camera from the video window is also challenging. Yet beyond these design challenges, what was common to all our couples was that they described sex-no matter how far they took itentirely as an extension of intimacy. That is, it wasn't so much about the sex, but rather about being together and being intimate together. This further exemplifies the role of presence in supporting and maintaining LDRs.

Idealization. We also found that couples in our study did not idealize about their relationship in the same ways that the existing literature has described LDRs [5,23,28]. Most partners discussed conflicting topics and they had very realistic views (as opposed to idealized ones) of the nature of their relationship. While we cannot draw any causal conclusions, we hypothesize that this reduced idealization was at least partially due to the manner in which our participants used the video link to simulate shared living and promote behaviors more similar to face-to-face relationships. Further study is warranted to fully investigate this aspect though.

\section{CONCLUSION}

Our paper has detailed the ways in which couples in longdistance relationships stay connected by using a video chat system. In particular, we have explored situations where partners hang out together by leaving their video chat system running over extended periods of time. Overall, our research suggests an avenue of design that directly supports creating a shared sense of presence between partners in long-distance relationships. Feeling intimately connected to a remote partner is not just about saying 'I love you.' It is about being a part of his or her life, about being day-to-day companions. Video chat is one tool that supports this, despite its limitations and challenges. We suggest that designers, researchers, and practitioners consider other mediums in addition to video to explore how they too can provide a rich experience that allows partners to feel like they are a part of their remote companion's life.

Our findings point the way, but we recognize its limitations. First, our participants may not be representative of the population at large. They were all of younger ages, reasonably savvy about technology, and comfortable enough to talk - quite openly-about how they used video chat. Second, most were (broadly) part of Western culture, although a few were from regions outside of Europe and North America. LDRs in other cultures and other demographics may appropriate and use video chat systems in different ways, and have different views and behaviors when it comes to on intimacy, sexual activities, and relationships. Some may even be opposed to utilizing a video link in the same way as our participants. In spite of these caveats, our participants were uniform in how they 
viewed video as a way to maintain intimacy and to be present in each other's daily lives. We encourage others to continue this research and explore the cross-cultural variations that may exist in long-distance relationships.

\section{ACKNOWLEDGMENTS}

This research was funded by the Natural Sciences and Engineering Research Council and the GRAND NCE as part of the AFEVAL project. We thank our participants for sharing intimate details about their relationships.

\section{REFERENCES}

1. Aguila, A.P.N. Living Long Distance Relationships through Computer-Mediated Communication, Social Science Diliman 5:1-2, (2009), 83-106.

2. Ames, M., Go, J., Kaye, J., Spasojevic, M., Making Love in the Network Closet: The Benefits and Work of Family Videochat, Proc. CSCW, ACM Press (2010).

3. Bardzell, J., and Bardzell, S. Pleasure is Your Birthright: Digitally Enabled Designer Sex Toys as a Case of Third-Wave HCI, Proc. CHI, ACM Press (2011).

4. Canary, D., and Stafford, L. Maintaining Relationships through Strategic Routine Interactions, Communication \& Relational Maintenance, Academic Press, (1994).

5. Dainton, M., and Aylor, B. Patterns of communication channel use in the maintenance of long distance relationships, Communication Research Reports, 19, (2002), 118-129.

6. Dimmick, J., Kline, S., and Stafford, L. The gratification niches of personal email and the telephone: Competition, displacement, and complementarity, Communication Research, 27, 227-248.

7. Dindia, K., and Emmers-Sommer, T.M. What partners do to maintain their close relationships, In Close relationships: Functions, forms and processes, New York: Psychology Press (2006), 305-324.

8. Duck, S. W., Steady s(he) goes: Relational maintenance as a shared meaning system. In D. J. Canary \& L. Stafford (Eds.), Communication and relational maintenance, San Diego, CA: Academic Press (1994)

9. Johnson, A.J., Haigh, M., Becker, J., Craig, E., and Wigley, S. College Students' Use of Relational Management Strategies in Email in Long-Distance and Geographically Close Relationships, J. Computer Mediated Communication, 13, 381-404, (2008).

10. Judge, T.K. and Neustaedter, C., Sharing Conversation and Sharing Life: Video Conferencing in the Home. Proc. CHI, ACM Press (2010), 655-658.

11.Judge, T.K., Neustaedter, C. and Kurtz, A., The Family Window: The Design and Evaluation of a Domestic Media Space. Proc. CHI, ACM Press (2010).

12.Judge, T. Neustaedter, C., Harrison, S., and Blose, A., The Family Portals: Connecting Families Through a Multifamily Media Space. Proc. ACM CHI, (2011).

13. Kaye, J. I just clicked to say I love you, Extended Abstracts of Proc. CHI, ACM Press (2006).
14.Kirk, D., Sellen, A., and Cao, X., Home Video Communication, Proc. CSCW, ACM Press (2010).

15. Neustaedter, C. and Judge, T. Peek-A-Boo: The Design of a Mobile Family Media Space, Video, Proc. Ubicomp, Springer (2010).

16. Pistole, M.C., Roberts, A., Chapman, M.L. Attachment, relationship maintenance, and stress in long distance and geographically close romantic relationships, J. Social and Personal Relationships, Vol. 27(4), (2010).

17.Pistole, M.C., Roberts, A., Mosko, J. Commitment Predictors: Long-Distance Versus Geographically Close Relationships, J. Counseling and Development, Spring 2010, Volume 88, (2010), 146-153.

18. Raffle, H., Ballagas, R., Revelle, G., Horii, H., Follmer, S., Go, J., Reardon, E., Mori, K., Kaye, J., and Spasojevic, M. (2010) Family story play: reading with children, Proc. CHI, ACM Press (2010).

19. Raffle, H., Revelle, G., Mori, K., Ballagas, R., Buza, K., Horii, H., Kaye, J., Cook, K., Freed, N., Go, J., Spasojevic, M. Hello, Is Grandma There? StoryVisit: Family Video Chat and Connected E-Books, Proc. CHI, ACM Press (2011).

20. Rumbough, T., The development and maintenance of interpersonal relationships through computer-mediated communication, J. Communication Research, 18(3).

21.Shirazi, A., Alt, F., Schmidt, A., Sarjanoja, A., Hynninen, L., Hakkila, J., and Holleis, P. Emotion Sharing via Self-Composed Melodies on Mobile Phones, Proc. Mobile HCI, ACM Press, (2009).

22. Stafford, L. Maintaining Long-Distance and CrossResidential Relationships, Lawrence Erlbaum, (2005).

23. Stafford, L. Geographic Distance and Communication During Courtship, J. Communication Research, 37(2), (2010), 275-297.

24. Stafford, L., \& Canary, D. J., Maintenance strategies and romantic relationship type, gender, and relational characteristics, J. Social and Personal Relationships, 8, (1991), 217-242.

25. Stafford, L., Merolla, A., and Castle, J. When longdistance dating partners become geographically close, J. Social and Personal Relationships, 23 (6), (2006), 901-919.

26. Stafford, L., and Reske, J. Idealization and Communication in Long Distance Premarital Relationships, J. Family Relations, 39 (3), (1990).

27. Strauss, A. and Corbin, J. Basics of Qualitative Research, 2nd Edition, Sage Publications (1998).

28. Vangelisti, A., and Huston, T. Maintaining Marital Satisfaction and Love, Communication and Relational Maintenance, Academic Press, (1994).

29. Yarosh, S., Cuzzort, S., Mueller, H., and Abowd, G.D., Developing a Media Space for Remote Synchronous Parent-Child Interaction, Proc IDC, ACM Press (2009). 